\title{
Opioids and adverse outcomes in elderly chronic obstructive pulmonary disease patients
}

\author{
To the Editor:
}

We read with interest the study by Vozonis et al. [1] describing the risk of adverse outcomes associated with opioid use in elderly chronic obstructive pulmonary disease (COPD) patients. There is currently a strong debate on the prescription of opioids in patients with COPD. While several studies seemed to demonstrate the harmlessness of opioids in this population [2-4], two recent studies including the one by VOzORIs et al. [1] challenge this result [5]. The large number of included patients and the excellent method used in these two studies strongly support the idea of an excess morbidity or mortality associated with the opioid use in COPD patients. There is, however, one limitation that needs to be taken into consideration.

Vozoris et al. [1] explain that patients receiving palliative care in the year prior to the index date were excluded. This seems appropriate since the use of morphine is recommended in the treatment of end-of-life dyspnoea. Nevertheless, we believe that this exclusion criterion is not strict enough to avoid a bias in the analysis and interpretation of mortality risk. Indeed, discussion of palliative care in COPD patients often arises in the context of acute respiratory failure [6]. Over half of pulmonologists claimed that end-of-life decisions in COPD patients occur during/after a major exacerbation [7,8]. It is unlikely that patients receiving opioid drugs following a recent end-of-life decision were excluded from the study by Vozoris et al. [1]. This potential bias may explain why no significant association was observed between opioid use and intensive care unit admissions in both the primary analysis and the sensitive analysis. Thus, the mortality results should be interpreted with caution.

In conclusion, the debate on the safety of morphine in COPD patients will remain open until further prospective studies refute or confirm the results published by Vozonis et al. [1]. Based on table 3 in their article [1], a randomised placebo controlled study would require the inclusion of 17664 patients to detect a significant difference (alpha $=0.05$ and power $=0.8$ ) in COPD or pneumonia-related mortality, while 7746 patients would be necessary to detect a difference in all-cause mortality.

@ERSpublications

Opioids in patients with COPD: results of mortality should be interpreted with caution regarding exclusion criteria http://ow.ly/IJbd304nC36

Damien Viglino $^{1,2}$ and Maxime Maignan ${ }^{1,2}$

${ }^{1}$ University Hospital Grenoble Alps - Emergency Dept and Mobile Intensive Care Unit, Grenoble, France. ${ }^{2}$ INSERM U1042, HP2 Laboratory, University Grenoble Alps, Grenoble, France.

Correspondence: Damien Viglino, Service des Urgences, CHU Grenoble Alpes, CS 10217, 38043 Grenoble cedex 9, France. E-mail: dviglino@chu-grenoble.fr

Received: Aug 122016 | Accepted: Aug 142016

Conflict of interest: None declared.

\section{References}

1 Vozoris NT, Wang X, Fischer HD, et al. Incident opioid drug use and adverse respiratory outcomes among older adults with COPD. Eur Respir J 2016; 48: 683-693.

2 Jennings A-L, Davies AN, Higgins JPT, et al. A systematic review of the use of opioids in the management of dyspnoea. Thorax 2002; 57: 939-944.

3 Currow DC, McDonald C, Oaten S, et al. Once-daily opioids for chronic dyspnea: a dose increment and pharmacovigilance study. J Pain Symptom Manage 2011; 42: 388-399.

4 Rocker GM, Simpson AC, Young J, et al. Opioid therapy for refractory dyspnea in patients with advanced chronic obstructive pulmonary disease: patients' experiences and outcomes. CMAJ Open 2013; 1: E27-E36.

5 Ekström MP, Bornefalk-Hermansson A, Abernethy AP, et al. Safety of benzodiazepines and opioids in very severe respiratory disease: national prospective study. BMJ 2014; 348: g445.

6 Carlucci A, Guerrieri A, Nava S. Palliative care in COPD patients: is it only an end-of-life issue? Eur Respir Rev 2012; 21: 347-354.

7 McNeely PD, Hébert PC, Dales RE, et al. Deciding about mechanical ventilation in end-stage chronic obstructive pulmonary disease: how respirologists perceive their role. CMAJ 1997; 156: 177-183.

8 Gaspar C, Alfarroba S, Telo L, et al. End-of-life care in COPD: a survey carried out with Portuguese pulmonologists. Rev Port Pneumol 2014; 20: 123-130. 
We thank D. Viglino and M. Maignan for their interest in our manuscript [1] and for their insightful comments. They raise a valid point that our mortality results may have been influenced by the potentially confounding effects of palliative care receipt on or following the index date. While we excluded individuals receiving palliative care in the year prior to the index date, we did not do so on or after the index date for practical methodological reasons. However, several points should be considered. First, Viglino and Maignan write that the decision to palliate in chronic obstructive pulmonary disease (COPD) often arises in the context of an acute respiratory exacerbation. Our propensity score model included whether or not a recent acute respiratory exacerbation occurred in the 30 days prior to the index date, and opioid users and nonusers were well balanced on that variable after propensity score weighting [1]. Second, increased respiratory-related and all-cause mortality were found not only among users of opioid-only agents but also among users of combination opioid/nonopioid formulations [1]. Opioids combined with paracetamol or aspirin are unlikely to be used for purposes of palliation and such agents represent $\sim 90 \%$ of incident opioid use among older adults with COPD [2]. Third, while the possible residual inclusion of individuals receiving palliative care among opioid users may potentially explain the finding of increased mortality, this would be unlikely to explain why risks of outpatient respiratory exacerbations and emergency visits for COPD or pneumonia were also greater among opioid users. If there was residual inclusion of individuals with recent end-of-life decisions among opioid users in our study, this would have been likely to bias the intensive care admission outcome towards being significantly decreased among opioid users, and not rendered a nonsignificant association, as Viglino and Maignan propose.

Viglino and Maignan indicate that further clinical trials are needed to help clarify the issue of the respiratory safety of opioids in COPD. However, clinical trials in isolation may not provide a complete picture regarding possible drug harms. As Viglino and Maignan suggest, clinical trials often include insufficient numbers of participants to identify potential risks of drug harm that are likely to occur in a minority of individuals, and trials involving participant numbers that Viglino and Maignan outline would be likely to be cost-prohibitive and unfeasible. Furthermore, clinical trials are commonly characterised by other features that limit their ability to evaluate possible drug harms: exclusion of individuals at risk of drug-related adverse events (such as older adults and those with comorbid illnesses); examination of limited drug dosing; and significant participant drop-out. Observational studies, such as ours, can overcome some of these limitations by including larger numbers of individuals, from the broader population, and "real-world" drug use. As a result, observational drug studies can help complement findings from clinical trials and both together can provide useful information to better guide therapy decision-making [3]. with COPD http://ow.ly/kGTL304qEe5

Nicholas T. Vozoris ${ }^{1,2,3}$, Denis E. O’Donnell ${ }^{4}$ and Sudeep S. Gill ${ }^{4,5}$

${ }^{1}$ Division of Respirology, Dept of Medicine, St Michael's Hospital, Toronto, ON, Canada. ${ }^{2}$ Keenan Research Centre, Li Ka Shing Knowledge Institute, St Michael's Hospital, Toronto, ON, Canada. ${ }^{3}$ Dept of Medicine, University of Toronto, Toronto, ON, Canada. ${ }^{4}$ Dept of Medicine, Queen's University, Kingston, ON, Canada. ${ }^{5}$ Institute for Clinical Evaluative Sciences, Toronto, ON, Canada.

Correspondence: Nicholas T. Vozoris, Division of Respirology, Dept of Medicine, St Michael's Hospital, 30 Bond Street, Toronto, ON, M5B 1W8, Canada. E-mail: nick.vozoris@utoronto.ca

Received: Aug 242016 | Accepted: Aug 302016

Conflict of interest: Disclosures can be found alongside this article at erj.ersjournals.com

\section{References}

1 Vozoris NT, Wang X, Fischer HD, et al. Incident opioid drug use and adverse respiratory outcomes among older adults with COPD. Eur Respir J 2016; 48: 683-693.

2 Vozoris NT, Wang X, Fischer HD, et al. Incident opioid drug use among older adults with chronic obstructive pulmonary disease: a population-based cohort study. Br J Clin Pharmacol 2016; 81: 161-170.

3 Vandenbroucke JP, Psaty BM. Benefits and risks of drug treatments: how to combine the best evidence on benefits with the best data about adverse effects. JAMA 2008; 300: 2417-2419. 